\title{
Clues to Mortality Trends and Their Related Factors in IgG4-related Disease: a Japanese Single-center Retrospective Study
}

Hiroyuki Kawahara

Kanazawa University Hospital

Ichiro Mizushima ( $\square$ ichiro7753@yahoo.co.jp )

Kanazawa University Hospital

Shunsuke Tsuge

Kanazawa University Hospital

Seung Shin

Kanazawa University Hospital

\section{Takahiro Yoshinobu}

Kanazawa University Hospital

\section{Ryohei Hoshiba}

Kanazawa University Hospital

\section{Ryo Nishioka}

Kanazawa University Hospital

\section{Takeshi Zoshima}

Kanazawa University Hospital

\section{Satoshi Hara}

Kanazawa University Hospital

Kiyoaki Ito

Kanazawa University Hospital

\section{Mitsuhiro Kawano}

Kanazawa University Hospital

\section{Research Article}

Keywords: IgG4-related disease, mortality, standardized mortality ratio, malignancy

Posted Date: November 12th, 2021

DOI: https://doi.org/10.21203/rs.3.rs-1063841/v1

License: (a) (1) This work is licensed under a Creative Commons Attribution 4.0 International License. Read Full License 


\section{Abstract}

Background: Few observations on the long-term prognosis have been conducted in immunoglobulin G4-related disease (IgG4-RD) patients with various organ involvement, not limited to autoimmune pancreatitis. Especially, mortality and its related factors in patients with IgG4-RD with various organ involvement are not well known. This study aimed to clarify mortality trends and its related factors in IgG4-RD with various organ involvement.

Methods: We retrospectively reviewed the medical records of patients with IgG4-RD at a single center in Japan. We calculated the crude mortality rate and the standardized mortality ratio (SMR) using national Japan mortality statistics and investigated the cause of death. We performed Cox regression analyses to assess mortality-related factors.

Results: A total of 179 patients with IgG4-RD were included and the median follow-up from diagnosis was 47 months (IQR 19-96). Ten patients (5.6\%) in our cohort died during the follow-up period. The crude mortality rate was 11.1 per 1,000 person-years. According to national Japan mortality statistics, 11.6 age- and sexmatched deaths would have been expected to occur within the follow-up period, resulting in an SMR of 0.86 (95\% confidence interval [Cl] 0.41-1.59). Univariate Cox regression analyses indicated that the number of affected organs at diagnosis (hazard ratio [HR] 1.45, 95\% Cl 1.02-2.05), eGFR $<45 \mathrm{~mL} / \mathrm{min} / 1.73 \mathrm{~m}^{2}$ at diagnosis (vs. $\geq 45, \mathrm{HR} 8.48,95 \% \mathrm{Cl} 2.42-29.79$ ), and the presence of malignancy during the clinical course (HR $3.93,95 \% \mathrm{Cl} 1.10-14.02)$ had a significant impact on the time to death.

Conclusions: Our findings suggested that IgG4-RD does not significantly affect long-term patient survival. On the other hand, multi-organ involvement and renal dysfunction as well as malignancy might be associated with higher mortality trends in IgG4-RD. Early detection and appropriate management of risk factors may improve the long-term prognosis of IgG4-RD.

\section{Background}

Immunoglobulin G4-related disease (IgG4-RD) is a multi-organ, fibro-inflammatory condition with massforming lesions, organ-swelling, and/or hypertrophic lesions due to dense lymphoplasmacytic infiltrates with IgG4 positive plasma cells ${ }^{1}$ ). In this disease, an elevation of serum IgG4 levels is a characteristic serological finding, seen in most cases. Generally, patients with this disease respond well to glucocorticoid therapy, but frequently relapse.

Despite a good response to glucocorticoid, the long-term prognosis of IgG4-RD is not always favorable. As mentioned above, relapses are common, with past reports describing relapse rates of $21-46 \%^{2-4}$. If not treated early and appropriately, progressive fibrosis in the affected organs causes persistent organ dysfunction, such as chronic salivary and lacrimal gland dysfunction due to IgG4-related dacryoadenitis and sialadenitis ${ }^{5}$ ) and diabetes mellitus and pancreatic exocrine insufficiency due to type 1 autoimmune pancreatitis (AIP $)^{6,7)}$. Particularly, serious complications in IgG4-RD include biliary obstruction, cirrhosis, and portal hypertension due to IgG4-related sclerosing cholangitis (IgG4-SC) $)^{6,7)}$, renal dysfunction due to $\lg G 4$-related kidney disease ${ }^{8,9)}$ or IgG4-related retroperitoneal fibrosis causing ureteral obstruction ${ }^{10)}$, and aortic aneurysm formation and/or aortic dissection due to IgG4-related periaortitis ${ }^{11}$ ). Furthermore, some recent studies have focused on the 
potential risk of malignancy in IgG4-RD patients which also can worsen the long-term prognosis of patients. In fact, the mortality is reported to be significantly higher in AIP/IgG4-SC than that in the general population, with an estimated odds ratio of $2.07^{6}$ ). In addition, cardiovascular events are more common in the elderly and affect their prognosis. Because IgG4-RD generally occurs in the elderly ${ }^{1)}$, cardiovascular events may also affect the prognosis of patients with this disease. However, an impact of cardiovascular events on the prognosis of patients with IgG4-RD has not been sufficiently investigated.

Few observations on the long-term prognosis have been conducted in IgG4-RD patients with various organ involvement, not limited to autoimmune pancreatitis. Especially, mortality trends and its related factors in patients with IgG4-RD are not well known. Therefore, we undertook the present study to clarify mortality trends compared to the general population in Japan and to identify factors associated with mortality in IgG4-RD with various organ involvement.

\section{Methods}

\section{Patients and Materials}

Between January 1, 2014, and December 31, 2020, we included 179 consecutive patents with IgG4-RD. The diagnosis of IgG4-RD was made by experts based on fulfillment of the Japanese comprehensive diagnostic criterial $^{12)}$ and/or the 2019 ACR/EULAR classification criteria for IgG4-RD ${ }^{13)}$.

Retrospectively reviewing the medical records, we determined the following clinical factors at the time of diagnosis: age; gender; presence or absence of allergy, dyslipidemia, hypertension, diabetes mellitus, smoking history, and cardiovascular diseases; serum levels of $\operatorname{lgG}$, IgG4, IgE, CH50, C3, C4, C-reactive protein (CRP), and creatinine; estimated glomerular infiltration rate (eGFR) calculated on the basis of a 3-variable Japanese equation ${ }^{14)}$; peripheral blood eosinophil counts; presence or absence of rheumatoid factor (RF), anti-nuclear antibody (ANA), and various disease-specific autoantibodies including SSA/Ro antibody, anti-neutrophil cytoplasmic antibody (ANCA), double-stranded DNA antibody, and anti-citrullinated protein antibody (ACPA); number of affected organs; involvement of pancreas, salivary glands, lacrimal glands, kidney, aorta/artery, retroperitoneum, and lung. We also determined presence or absence of malignancy, relapse, and death during the observation periods. Presence of malignancy during the observation periods was defined as having malignancy at or after the diagnosis of IgG4-RD.

Using the collected data, we calculated the all-cause and malignancy-related mortality rate and the standardized mortality ratio (SMR) using national Japan mortality statistics and investigated the cause of death. Incidence of malignancy during the clinical course and standardized incidence ratio (SIR) were also calculated using Cancer Statistics provided by Cancer Information Service, National Cancer Center, Japan (Vital Statistics of Japan, Ministry of Health, Labour and Welfare).

\section{Statistical Analysis}

Statistical analysis was performed using SPSS V.25 (IBM Corp., Armonk, NY, USA). Data are presented as median (interquartile range [IQR1, IQR3]) for continuous variables. 
The significance of differences between groups was determined using Mann-Whitney $U$ test, while the significance of differences in frequencies was analyzed with Fisher's exact probability test. Factors related to mortality were assessed by Cox regression analysis. For the time-to-event analysis, we considered that the follow-up of the patients started at the time of diagnosis and was terminated at the time of the end of the observation period (December 31, 2020), loss of follow-up, or death. In these Cox regression analyses, for continuous variables, units for increments to calculate hazard ratios were set at 1 year for age; $100 \mathrm{mg} / \mathrm{dL}$ for serum IgG4 levels; $1 \mathrm{mg} / \mathrm{dL}$ for serum creatinine and CRP levels; $10 \mathrm{~mL} / \mathrm{min} / 1.73 \mathrm{~m}^{2}$ for eGFR. Receiver operating characteristic (ROC) curve analyses were performed to test the usefulness of certain parameters for the prediction of mortality and to determine the appropriate cut-off values. According to the presence or absence of the detected risk factors, survival rates were calculated using the Kaplan-Meier method. Log-rank test was used to compare survival times of patients with and without malignancies. Significant differences were recognized at $\mathrm{P}<0.05$.

\section{Results}

One hundred and seventy-nine patients with IgG4-RD were included. Patients' characteristics were listed in Table 1. One hundred and twenty-four were male (69.3\%); the median age was 68 years (interquartile range [IQR] 60-75 years); and the median follow-up period from diagnosis was 47 months (IQR 19-96). Median number of involved organs was 2.0 (IQR 1.0-4.0). Involved organs were predominantly salivary glands (56.4\%), lacrimal glands (50.2\%), kidney (29.6\%), pancreas (29.5\%), aorta/artery (28.4\%), and retroperitoneum (5.0\%). Median serum IgG4 and CRP levels were $434 \mathrm{mg} / \mathrm{dL}$ (IQR 224-916) and $0.10 \mathrm{mg} / \mathrm{dL}$ (IQR 0.04-0.30), respectively. Malignancy and relapse during the clinical course were found in $23(12.8 \%)$ and 27 cases (15.1\%), respectively.

Ten patients (5.6\%) in our cohort died during the follow-up period (Table 2). Five died of malignancy, one of respiratory failure, two of infectious pneumonia, one of sudden cardiac event, and one of suspected aortic aneurysmal rupture. Median period from diagnosis to death was 44 months (IQR 28-79). The crude all-cause mortality rate was 11.1 per 1,000 person-years. According to national Japan mortality statistics, 11.6 age- and sex-matched deaths would have been expected to occur within the follow-up period, resulting in an SMR of 0.86 (95\% confidence interval [Cl] 0.41-1.59). The cancer-related mortality was not significantly increased compared with the general population (4.42 expected deaths versus 5 observed deaths; SMR $1.13,95 \% \mathrm{Cl} 0.36$ 2.64). On the other hand, according to the Cancer Statistics in Japan, the expected number of cases of ageand sex-matched malignancies to occur within the follow-up period would be 12.7. The actual number of cases with malignancies was 23 in this cohort. Therefore, there was an increased SIR of $1.81(95 \% \mathrm{Cl} 1.14$ 2.71) for all malignancies compared with the general population.

To clarify the characteristics of the non-surviving group, we compared various clinical features of the surviving and non-surviving groups using Mann-Whitney $U$ test and Fisher's exact probability test (Table 1 ). The serum levels of IgE, CRP, and creatinine as well as the frequency of malignancy in the non-surviving group were significantly higher than those in the surviving group, whereas eGFR was significantly lower in the nonsurviving group. 
Factors related to mortality trends were assessed by univariate Cox regression analysis (Table 3), which indicated that the number of affected organs at diagnosis (hazard ratio [HR] 1.45, 95\% $\mathrm{Cl} 1.02-2.05$ ),

involvement of $\geq 4$ organs at diagnosis (vs. $\leq 3$ organs, HR 3.87, 95\% Cl 1.09-13.75), serum creatinine levels at diagnosis (HR 1.82, 95\% Cl 1.06-3.12), eGFR at diagnosis (HR 0.68, 95\% Cl 0.51-0.91), eGFR of less than 45 $\mathrm{mL} / \mathrm{min} / 1.73 \mathrm{~m}^{2}$ at diagnosis (vs. $\geq 45 \mathrm{~mL} / \mathrm{min} / 1.73 \mathrm{~m}^{2}, \mathrm{HR} 8.48,95 \% \mathrm{Cl}$ 2.42-29.79), and the presence of malignancy during the clinical course (vs. absence, $\mathrm{HR} 3.71,95 \% \mathrm{Cl} 1.05-13.02$ ) all had a significant impact on the time to death, whereas the other factors including age at diagnosis (HR 1.06, 95\% $\mathrm{Cl} 0.99-1.12)$ and serum CRP (HR 1.19, 95\% Cl 0.79-1.79) and lgG4 levels (HR 1.02, 95\% Cl 0.93-1.11) at diagnosis did not. Presence of dyslipidemia (HR 1.16, 95\% Cl 0.33-4.12), hypertension (HR 1.68, 95\% Cl 0.47-5.96), diabetes mellitus (HR 0.33, $95 \% \mathrm{Cl} 0.07-1.55)$, smoking history ( $\mathrm{HR} 2.50,95 \% \mathrm{Cl} 0.53-11.82)$, and cardiovascular diseases $(\mathrm{HR} 2.08,95 \% \mathrm{Cl}$ 0.54-8.06) did not have a significant impact on the time to death either.

To help determine the extent to which the number of affected organs and eGFR can contribute to the reliable prediction of mortality during the clinical course, and to identify their appropriate cut-offs, we used ROC curves (Figure 1). Concerning the number of affected organs, the area under the ROC curve was 0.640 ( $95 \% \mathrm{Cl}$ : $0.433-0.846, P=0.137)$, suggesting that this parameter does not accurately predict mortality. However, we found that multiple organ involvement in more than 4 organs was the most appropriate cut-off and yielded a sensitivity of $60.0 \%$ and specificity of $72.7 \%$ in predicting mortality (Figure $1 \mathrm{~A}$ ). Concerning eGFR, the area under the ROC curve was 0.717 (95\% Cl: 0.544-0.889, P=0.021). We found that eGFR of less than 73.6 $\mathrm{mL} / \mathrm{min} / 1.73 \mathrm{~m}^{2}$ was a sensitive cut-off that yielded a sensitivity of $90.0 \%$ and specificity of $47.6 \%$ and eGFR of less than $38.9 \mathrm{~mL} / \mathrm{min} / 1.73 \mathrm{~m}^{2}$ was a specific cut-off that yielded a sensitivity of $50.0 \%$ and specificity of $91.7 \%$ in predicting mortality (Figure $1 \mathrm{~B}$ ).

According to the presence or absence of malignancy, $\geq 4$ affected organs or $\leq 3$ at diagnosis, and eGFR of $<45$ or $\geq 45 \mathrm{~mL} / \mathrm{min} / 1.73 \mathrm{~m}^{2}$ at diagnosis, survival rates were calculated using the Kaplan-Meier method. KaplanMeier analyses also showed significant differences in the cumulative rates of death between patients with and without malignancy during the clinical course $(P=0.028)$ (Figure $2 A), \geq 4$ affected organs at diagnosis $(P=0.024)$ (Figure $2 B$ ), and eGFR of $<45 \mathrm{~mL} / \mathrm{min} / 1.73 \mathrm{~m}^{2}$ at diagnosis $(P<0.01)$ (Figure $2 \mathrm{C}$ ).

\section{Discussion}

The present study analyzing 179 patients with IgG4-RD showed that the all-cause mortality trends of patients with IgG4-RD did not significantly differ from those of the age- and sex-matched Japanese population. The malignancy-related mortality was not increased compared with the matched Japanese population, but the incidence of malignancy was increased. Multi-organ involvement and renal dysfunction at diagnosis as well as malignancy developing during the clinical course were associated with higher mortality trends. Especially, the cumulative survival rate was significantly lower in the patients with malignancy compared with those without. These new findings may provide clues to better long-term management and screening of IgG4-RD.

Although several studies have analyzed the long-term prognosis of IgG4-RD, it has not been fully elucidated because of its rarity. The nationwide epidemiological survey of 1,370 Japanese patients with AIP in 2016 ${ }^{15}$ ) reported that $37(2.7 \%)$ patients died within approximately two years of the diagnosis. Huggett et al ${ }^{6)}$ studied 115 patients with AIP/lgG4-SC and found that 11 patients (10\%) died during a mean follow-up of 33 months. 
Using National UK mortality statistics, the authors suggested that there was an increased all-cause mortality ratio of 2.07 ( $95 \% \mathrm{Cl} 1.07-3.55)$. In our study of 179 patients with IgG4-RD, 10 patients (5.5\%) died during the follow-up. There was no significant increase in the mortality trends compared to the age-and sex-matched population in Japan. This result was contrary to the previous report by Huggett et a ${ }^{6}$ ), but this might be due to the fact that our cases, unlike the cases of Huggett et al ${ }^{6}$, had not only AIP/IgG4-SC but also various affected organs including mainly salivary and lacrimal gland lesions. On the other hand, these results suggest that, with proper management, the prognosis of patients with IgG4-RD may be similar to that of the general population.

Some recent studies have focused on the potential risk of malignancy in patients with IgG4-RD. Conflicting studies have noted both an increased occurrence of malignancies in this group ${ }^{6,15-22)}$ and no such increase in others ${ }^{23,24)}$, making the association between IgG4-RD and malignancy controversial even now. In our study, the risk of any malignancy at diagnosis or during follow-up was increased (SIR $1.81,95 \% \mathrm{Cl} 1.14-2.71)$ when compared with the matched national population. In addition, Cox regression analysis indicated that malignancy during the clinical course had a significant impact on the time to death. The Kaplan-Meier survival curve also showed that all-cause mortality increased during the clinical course in the patients with malignancy as compared to those without. These results suggest that the periodical screening of systemic organs in patients with IgG4-RD may lead to a further improvement of their prognosis through the early detection and treatment of malignancy.

Furthermore, we found that the number of affected organs and renal dysfunction at diagnosis were associated with mortality trends in IgG4-RD. The number of affected organs is recognized as one of the factors reflecting disease activity in general, and it may also be related to long-term prognosis. Accordingly, the periodical screening of systemic organs is also important for the early detection of subclinical new or recurrent organ involvement. On the other hand, acute kidney injury ${ }^{25,26)}$ and chronic kidney disease ${ }^{27)}$ are known to be associated with patient mortality, and this study also suggested that renal dysfunction was an important prognostic factor in IgG4-RD. Our ROC analysis demonstrated eGFR $<73.6 \mathrm{~mL} / \mathrm{min} / 1.73 \mathrm{~m}^{2}$ to be a sensitive cut-off and eGFR $<38.9 \mathrm{~mL} / \mathrm{min} / 1.73 \mathrm{~m}^{2}$ a specific cut-off for prediction of mortality. Of note, IgG4-RKD was not diagnosed in 2 of the 5 non-surviving patients with $<38.9 \mathrm{~mL} / \mathrm{min} / 1.73 \mathrm{~m}^{2}$ in this study (Table 2), meaning that renal dysfunction due to not only IgG4-RKD but also any other causes may be associated with a poor prognosis. In patients with IgG4-RD, therefore, it is necessary to also pay attention to the presence of these factors. On the other hand, further studies are necessary to clarify which therapeutic interventions improve the prognosis of patients with multiple organ involvement and/or renal dysfunction.

In this study, cardiovascular events and their classical risk factors, an important cause and risk factors of death in the general population, respectively, were not clearly associated with the mortality trends in patients with IgG4-RD despite glucocorticoid maintenance therapy. Cardiovascular events and their classical risk factors are more common in the elderly irrespective of having IgG4-RD or not and affect their prognosis. Although IgG4-RD is more prevalent in the elderly ${ }^{1}$ ), an impact of cardiovascular events and their risk factors on the prognosis of patients with IgG4-RD was not evident in the present cohort. However, in IgG4-related periarteritis, aneurysm or rupture of the affected aorta/artery and/or ischemic events in the coronary arterial lesions are recognized as fatal complications ${ }^{11}$ ), suggesting that cardiovascular events may be an important 
cause of death depending on the affected organ in IgG4-RD. It is important to further investigate and clarify the impact of cardiovascular events on the long-term prognosis of this disease in multicenter studies with a larger number of patients.

There are some limitations in this study. First, it was designed as a single-center cohort study. We should confirm the results in populations with different characteristics such as race, affected organ, and treatment. Second, in assessing the incidence of malignancy, this study had a possible risk of ascertainment bias because the incidence of malignancy may be elevated by earlier detection in patients receiving various radiological examinations for follow-up of IgG4-RD. Finally, we should treat conclusions drawn from a comparison with national statistics with caution, because the analysis was not adjusted for other risk factors such as smoking, alcohol intake, and obesity. The cohort size was relatively large for this rare disease, but the number of the patients who died was not sufficient to perform multivariate analysis. Further studies involving more patients are needed.

In conclusion, our findings suggested that IgG4-RD does not significantly affect long-term patient survival. On the other hand, multi-organ involvement and renal dysfunction at diagnosis as well as malignancy during the clinical course might be associated with higher mortality trends in IgG4-RD. Early detection of risk factors and appropriate management and intervention are considered to be necessary to improve the long-term prognosis of IgG4-RD.

\section{Abbreviations}

ACPA: Anti-citrullinated protein antibody; ACR/EULAR: the American College of Rheumatology and the European League Against Rheumatism; AIP: type 1 autoimmune pancreatitis; ANA: Anti-nuclear antibody; ANCA: Anti-neutrophil cytoplasmic antibody; $\mathrm{CH} 50: 50 \%$ hemolytic unit of complement; Cl: Confidence interval; CRP: C-reactive protein; CVD: Cardiovascular disease; DL: Dyslipidemia; DM: Diabetes mellitus; eGFR: estimated glomerular filtration rate; HR: Hazard ratio; HT: Hypertension; IgE: Immunoglobulin E; IgG: Immunoglobulin G; IgG4: Immunoglobulin G4; IgG4-RD: Immunoglobulin G4-related disease; IgG4-SC: IgG4related sclerosing cholangitis; IQR: Interquartile range; RF: Rheumatoid factor; ROC: Receiver operating characteristic; SMR: Standardized mortality ratio; s/o: Suspect of.

\section{Declarations}

\section{Ethics approval and consent to participate}

This study was approved by the institutional ethics board of the Medical Ethics Committee of Kanazawa University, and informed consent for the use of all data was obtained from each patient. The research was conducted in compliance with the Declaration of Helsinki.

\section{Consent for publication}

Not applicable.

\section{Availability of data and materials}


The data used and/or analyzed during the present study will be available on reasonable request to the corresponding author.

\section{Competing interests}

The authors declare that they have no competing interests.

\section{Funding}

This work was supported by Health and Labour Sciences Research Grants for the Study of Intractable Diseases from the Ministry of Health, Labor and Welfare, Japan.

\section{Authors' contributions}

$\mathrm{HK}$ and IM designed the research, acquired data, contributed to analysis and interpretation of data, and drafted and revised the manuscript. ST, SS, TY, RH, RN, TZ, SH, and KI acquired data and provided intellectual content of critical importance to the work described. MK designed the research, acquired data, contributed to analysis and interpretation of data, provided intellectual content of critical importance to the work described, and revised the manuscript. All authors read and approved the final manuscript.

\section{Acknowledgements}

We thank John Gelblum for his critical reading of the manuscript.

\section{References}

1. Stone JH, Zen Y, Deshpande V. IgG4-related disease. N Engl J Med. 2012;366(6):539-51.

2. Campochiaro C, Ramirez GA, Bozzolo EP, Lanzillotta M, Berti A, Baldissera $E$, et al. IgG4-related disease in Italy: clinical features and outcomes of a large cohort of patients. Scand J Rheumatol. 2016;45(2):135-45.

3. Kubota K, Kamisawa T, Okazaki K, Kawa S, Hirano K, Hirooka Y, et al. Low-dose maintenance steroid treatment could reduce the relapse rate in patients with type 1 autoimmune pancreatitis: a long-term Japanese multicenter analysis of 510 patients. J Gastroenterol. 2017;52(8):955-64.

4. Yamada K, Yamamoto M, Saeki T, Mizushima I, Matsui S, Fujisawa Y, et al. New clues to the nature of immunoglobulin G4-related disease: a retrospective Japanese multicenter study of baseline clinical features of 334 cases. Arthritis Res Ther. 2017;19(1):262.

5. Shimizu Y, Yamamoto M, Naishiro Y, Sudoh G, Ishigami K, Yajima H, et al. Necessity of early intervention for IgG4-related disease--delayed treatment induces fibrosis progression. Rheumatology (Oxford). 2013;52(4):679-83.

6. Huggett MT, Culver EL, Kumar M, Hurst JM, Rodriguez-Justo M, Chapman MH, et al. Type 1 autoimmune pancreatitis and IgG4-related sclerosing cholangitis is associated with extrapancreatic organ failure, malignancy, and mortality in a prospective UK cohort. Am J Gastroenterol. 2014;109(10):1675-83.

7. Lanzillotta M, Campochiaro C, Mancuso G, Ramirez GA, Capurso G, Falconi M, et al. Clinical phenotypes of IgG4-related disease reflect different prognostic outcomes. Rheumatology (Oxford). 2020;59(9):243542. 
8. Saeki T, Kawano M, Mizushima I, Yamamoto M, Wada Y, Nakashima H, et al. The clinical course of patients with IgG4-related kidney disease. Kidney Int. 2013;84(4):826-33.

9. Mizushima I, Yamamoto M, Inoue D, Nishi S, Taniguchi Y, Ubara Y, et al. Factors related to renal cortical atrophy development after glucocorticoid therapy in IgG4-related kidney disease: a retrospective multicenter study. Arthritis Res Ther. 2016;18(1):273.

10. Mizushima I, Kawano M. Renal Involvement in Retroperitoneal Fibrosis: Prevalence, Impact and Management Challenges. Int J Nephrol Renovasc Dis. 2021;14:279-89.

11. Akiyama M, Kaneko Y, Takeuchi T. Characteristics and prognosis of IgG4-related periaortitis/periarteritis: $A$ systematic literature review. Autoimmun Rev. 2019;18(9):102354.

12. Umehara H, Okazaki K, Masaki Y, Kawano M, Yamamoto M, Saeki T, et al. Comprehensive diagnostic criteria for IgG4-related disease (IgG4-RD), 2011. Mod Rheumatol. 2012;22:21-30.

13. Wallace ZS, Naden RP, Chari S, Choi HK, Della-Torre E, Dicaire JF, et al. The 2019 American College of Rheumatology/European League Against Rheumatism classification criteria for IgG4-related disease. Ann Rheum Dis. 2020;79(1):77-87.

14. Matsuo S, Imai E, Horio M, Yasuda Y, Tomita K, Nitta K, et al. Revised equations for estimated GFR from serum creatinine in Japan. Am J Kidney Dis. 2009;53(6):982-92.

15. Masamune A, Kikuta K, Hamada S, Tsuji I, Takeyama Y, Shimosegawa T, et al. Nationwide epidemiological survey of autoimmune pancreatitis in Japan in 2016. J Gastroenterol. 2020;55(4):462-70.

16. Asano J, Watanabe T, Oguchi T, Kanai K, Maruyama M, Ito T, et al. Association Between Immunoglobulin G4-related Disease and Malignancy within 12 Years after Diagnosis: An Analysis after Longterm Followup. J Rheumatol. 2015;42(11):2135-42.

17. Tang H, Yang H, Zhang P, Wu D, Zhang S, Zhao J, et al. Malignancy and IgG4-related disease: the incidence, related factors and prognosis from a prospective cohort study in China. Sci Rep. 2020;10(1):4910.

18. Ahn SS, Song JJ, Park YB, Lee SW. Malignancies in Korean patients with immunoglobulin G4-related disease. Int J Rheum Dis. 2017;20(8):1028-35.

19. Sekiguchi H, Horie R, Kanai M, Suzuki R, Yi ES, Ryu JH. IgG4-Related Disease: Retrospective Analysis of One Hundred Sixty-Six Patients. Arthritis Rheumatol. 2016;68(9):2290-9.

20. Yamamoto M, Takahashi H, Tabeya T, Suzuki C, Naishiro Y, Ishigami K, et al. Risk of malignancies in IgG4related disease. Mod Rheumatol. 2012;22(3):414-8.

21. Tang H, Yang H, Zhang P, Wu D, Zhang S, Zhao J, et al. Malignancy and IgG4-related disease: the incidence, related factors and prognosis from a prospective cohort study in China. Sci Rep. 2020;10(1):4910.

22. Okamoto A, Watanabe T, Kamata K, Minaga K, Kudo M. Recent Updates on the Relationship between Cancer and Autoimmune Pancreatitis. Intern Med. 2019;58(11):1533-9.

23. Inoue D, Yoshida K, Yoneda N, Ozaki K, Matsubara T, Nagai K, et al. IgG4-related disease: dataset of 235 consecutive patients. Medicine (Baltimore). 2015;94(15):e680.

24. Hirano K, Tada M, Sasahira N, Isayama H, Mizuno S, Takagi K, et al. Incidence of malignancies in patients with IgG4-related disease. Intern Med. 2014;53(3):171-6. 
25. Lassnigg A, Schmidlin D, Mouhieddine M, Bachmann LM, Druml W, Bauer P, et al. Minimal changes of serum creatinine predict prognosis in patients after cardiothoracic surgery: a prospective cohort study. $J$ Am Soc Nephrol. 2004;15:1597-605.

26. Chertow GM, Burdick E, Honour M, Bonventre JV, Bates DW. Acute kidney injury, mortality, length of stay, and costs in hospitalized patients. J Am Soc Nephrol. 2005;16:3365-70.

27. Matsushita K, van der Velde M, Astor BC, Woodward M, Levey AS, de Jong PE, et al. Association of estimated glomerular filtration rate and albuminuria with all-cause and cardiovascular mortality in general population cohorts: a collaborative meta-analysis. Lancet. 2010;375(9731):2073-81.

\section{Tables}

Table 1. Patient characteristics. 


\begin{tabular}{|c|c|c|c|c|}
\hline & $\begin{array}{l}\text { All patients } \\
(n=179)\end{array}$ & $\begin{array}{l}\text { Non-surviving } \\
\text { group }(n=10)\end{array}$ & $\begin{array}{l}\text { Surviving group } \\
(n=169)\end{array}$ & $\begin{array}{l}\mathrm{P}- \\
\text { value }\end{array}$ \\
\hline \multicolumn{5}{|l|}{ Characteristics and clinical course } \\
\hline Male & $124(69.3 \%)$ & $8(80.0 \%)$ & $116(68.6 \%)$ & 0.449 \\
\hline Age & $\begin{array}{l}68.0(60.0- \\
75.0)\end{array}$ & $68.5(61.0-79.5)$ & $68.0(59.5-74.5)$ & 0.318 \\
\hline Allergy (\%) & $95(53.1 \%)$ & $3(30.0 \%)$ & $92(54.4 \%)$ & 0.193 \\
\hline Diabetes Mellitus (\%) & $70(39.1 \%)$ & $2(20.0 \%)$ & $68(40.2 \%)$ & 0.203 \\
\hline Hypertension (\%) & $80(44.7 \%)$ & $6(60.0 \%)$ & $74(43.8 \%)$ & 0.316 \\
\hline Dyslipidemia (\%) & $62(34.6 \%)$ & $4(40.0 \%)$ & $58(34.3 \%)$ & 0.714 \\
\hline Smoking history (\%) & $111(62.7 \%)$ & $8(80.0 \%)$ & $103(61.6 \%)$ & 0.244 \\
\hline Cardiovascular disease (\%) & $32(18.4 \%)$ & $3(30.0 \%)$ & $29(17.6 \%)$ & 0.329 \\
\hline Observation periods (month) & $47(19-96)$ & $44.0(16-79)$ & $47(19-99)$ & 0.676 \\
\hline Number of affected organs & $2.0(1.0-4.0)$ & $4.0(1.8-5.5)$ & $2.0(1.0-4.0)$ & 0.128 \\
\hline $\begin{array}{l}\text { Presence of malignancy at or after } \\
\text { diagnosis (\%) }\end{array}$ & $23(12.8 \%)$ & $5(50.0 \%)$ & $18(10.7 \%)$ & $0.004^{*}$ \\
\hline Relapse (\%) & $27(25.1 \%)$ & $1(10.0 \%)$ & $26(15.4 \%)$ & 0.644 \\
\hline \multicolumn{5}{|l|}{ Laboratory Findings } \\
\hline Serum IgG level (mg/dL) & $\begin{array}{l}1951(1556- \\
2572)\end{array}$ & $2235(1960-2757)$ & $\begin{array}{l}1932(1538- \\
2572)\end{array}$ & 0.219 \\
\hline Serum IgG4 level (mg/dL) & $\begin{array}{l}434(224- \\
916)\end{array}$ & 717 (274-1093) & $409(224-864)$ & 0.400 \\
\hline Serum IgE level (IU/mL) & $\begin{array}{l}501(213- \\
1125)\end{array}$ & 1055 (518-2477) & $467(180-1068)$ & $0.026 *$ \\
\hline Serum C3 level (mg/dL) & $94(80-110)$ & $105(84-114)$ & $94(79-111)$ & 0.442 \\
\hline Serum C4 level (mg/dL) & $22(15-27)$ & $24(16-39)$ & $22(15-27)$ & 0.419 \\
\hline Serum CH50 level (U/mL) & $53(40-60)$ & $58(44-60)$ & $53(39-60)$ & 0.578 \\
\hline Serum CRP level (mg/dL) & $\begin{array}{l}0.10(0.04- \\
0.30)\end{array}$ & $0.40(0.18-1.20)$ & $0.10(0.03-0.30)$ & $0.004^{*}$ \\
\hline Serum creatinine level (mg/dL) & $\begin{array}{l}0.79(0.65- \\
1.00)\end{array}$ & $1.20(0.65-1.72)$ & $0.77(0.64-0.99)$ & $0.046 *$ \\
\hline eGFR (mL/min/1.73m²) & $\begin{array}{l}70.9(54.8- \\
85.4)\end{array}$ & $46.6(32.1-71.0)$ & $72.7(56.4-85.7)$ & $0.021 *$ \\
\hline Eosinophil count $(/ \mu \mathrm{L})$ & $\begin{array}{l}201(113- \\
342)\end{array}$ & $160(106-486)$ & $208(115-340)$ & 0.523 \\
\hline RF (\%) & $28(18.8 \%)$ & $1(11.1 \%)$ & $27(19.2 \%)$ & 0.543 \\
\hline
\end{tabular}




\begin{tabular}{|lllll|}
\hline ANA (\%) & $41(24.0 \%)$ & $3(30.0 \%)$ & $38(23.6 \%)$ & 0.625 \\
\hline Disease-specific antibodies (\%) & $21(13.2 \%)$ & $0(0 \%)$ & $21(13.2 \%)$ & 1.00 \\
\hline Affected organs & & & & \\
\hline Salivary gland (\%) & $101(56.4 \%)$ & $7(70.0 \%)$ & $94(55.6 \%)$ & 0.759 \\
\hline Lacrimal glands (\%) & $90(50.2 \%)$ & $4(40.0 \%)$ & $86(50.8 \%)$ & 0.512 \\
\hline Kidney (\%) & $53(29.6 \%)$ & $4(40.0 \%)$ & $49(29.0 \%)$ & 0.315 \\
\hline Pancreas (\%) & $52(29.5 \%)$ & $3(30.0 \%)$ & $49(29.0 \%)$ & 0.991 \\
\hline Aorta/artery (\%) & $51(28.4 \%)$ & $5(50.0 \%)$ & $46(27.2 \%)$ & 0.290 \\
\hline Lung/pleura (\%) & $34(19.0 \%)$ & $4(40.0 \%)$ & $30(17.8 \%)$ & 0.121 \\
\hline Retroperitoneum (\%) & $17(9.5 \%)$ & $1(10.0 \%)$ & $16(9.4 \%)$ & 0.991 \\
\hline
\end{tabular}

Note: Conversion factor for creatinine: $\mathrm{mg} / \mathrm{dL}$ to $\mu \mathrm{mol} / \mathrm{L}, \times 88.4$. Data are presented as median (IQR), or $\mathrm{n} / \mathrm{N}$ (\%). p values were calculated by Mann-Whitney U test or Fisher's exact test, as appropriate.

Abbreviations: IgG: immunoglobulin G; IgG4: immunoglobulin G4; IgE: immunoglobulin E; CH50: 50\% hemolytic unit of complement; CRP: C-reactive protein; eGFR: estimated glomerular filtration rate; RF: rheumatoid factor; ANA: anti-nuclear antibody; DM: diabetes mellitus; HT: hypertension; DL: dyslipidemia; CVD history: cardiovascular disease history.

Table 2. Characteristics of the 10 non-surviving patients 


\begin{tabular}{|c|c|c|c|c|c|c|c|}
\hline No & Age & Affected organ & $\begin{array}{l}\text { Serum } \\
\text { lgG4 } \\
\text { level } \\
\text { (mg/dL) }\end{array}$ & $\begin{array}{l}\text { eGFR } \\
\left(\mathrm{mL} / \mathrm{min} / 1.73 \mathrm{~m}^{2}\right)\end{array}$ & $\begin{array}{l}\text { Presence of } \\
\text { malignancy } \\
\text { at or after } \\
\text { diagnosis }\end{array}$ & $\begin{array}{l}\text { Cause of } \\
\text { death }\end{array}$ & $\begin{array}{l}\text { Time } \\
\text { after } \\
\text { diagnosis } \\
\text { of lgG4- } \\
\text { RD } \\
\text { (month) }\end{array}$ \\
\hline 1 & 77 & $\begin{array}{l}\text { salivary glands, } \\
\text { lacrimal glands, } \\
\text { kidney, lung, } \\
\text { lymph nodes }\end{array}$ & 984 & 73.4 & Absent & $\begin{array}{l}\text { Sudden } \\
\text { cardiac } \\
\text { event }\end{array}$ & 91 \\
\hline 2 & 70 & $\begin{array}{l}\text { pancreas, biliary } \\
\text { tract, salivary } \\
\text { glands, aorta }\end{array}$ & 1420 & 32.5 & Present & $\begin{array}{l}\text { Pancreatic } \\
\text { cancer }\end{array}$ & 140 \\
\hline 3 & 62 & $\begin{array}{l}\text { salivary glands, } \\
\text { lacrimal glands }\end{array}$ & 204 & 70.3 & Present & $\begin{array}{l}\text { Malignant } \\
\text { lymphoma }\end{array}$ & 2 \\
\hline 4 & 60 & aorta & 354 & 95.8 & Present & $\begin{array}{l}\text { Colon } \\
\text { cancer }\end{array}$ & 75 \\
\hline 5 & 61 & $\begin{array}{l}\text { salivary glands, } \\
\text { lung }\end{array}$ & 944 & 69.4 & Absent & $\begin{array}{l}\text { Respiratory } \\
\text { failure }\end{array}$ & 20 \\
\hline 6 & 61 & $\begin{array}{l}\text { salivary glands, } \\
\text { lacrimal glands, } \\
\text { kidney, lymph } \\
\text { nodes }\end{array}$ & 886 & 31.0 & Absent & $\begin{array}{l}\text { Severe } \\
\text { pneumonia }\end{array}$ & 75 \\
\hline 7 & 81 & $\begin{array}{l}\text { salivary glands, } \\
\text { kidney, aorta, } \\
\text { pleura, } \\
\text { paravertebral } \\
\text { lesion in the } \\
\text { thorax, prostate, } \\
\text { lymph nodes }\end{array}$ & 548 & 33.6 & Absent & $\begin{array}{l}\text { Recurrent } \\
\text { gastric } \\
\text { cancer }\end{array}$ & 3 \\
\hline 8 & 79 & pancreas & 10.7 & 26.4 & Present & $\begin{array}{l}\text { Sepsis, } \\
\text { pneumonia }\end{array}$ & 50 \\
\hline 9 & 67 & $\begin{array}{l}\text { lacrimal glands, } \\
\text { orbits, lung, } \\
\text { liver, aorta, } \\
\text { retroperitoneum, } \\
\text { pituitary gland, } \\
\text { submucosal } \\
\text { lesion in the } \\
\text { stomach, lymph } \\
\text { nodes }\end{array}$ & 2090 & 54.5 & Present & $\begin{array}{l}\text { Cancer of } \\
\text { unknown } \\
\text { primary }\end{array}$ & 38 \\
\hline 10 & 89 & $\begin{array}{l}\text { salivary glands, } \\
\text { kidney, } \\
\text { pancreas, aorta }\end{array}$ & 297 & 38.8 & Absent & $\begin{array}{l}\text { s/o aortic } \\
\text { aneurysmal } \\
\text { rupture }\end{array}$ & 30 \\
\hline
\end{tabular}

Abbreviations: eGFR, estimated glomerular filtration rate; s/o, suspect of.

Table 3. Univariate Cox regression analysis of factors associated with mortality 


\begin{tabular}{|c|c|c|c|}
\hline & HR & $95 \% \mathrm{Cl}$ & $P$ value \\
\hline Age & 1.06 & $0.99-1.12$ & 0.08 \\
\hline Male gender & 1.99 & $0.42-9.38$ & 0.38 \\
\hline Presence of malignancy at or after diagnosis & 3.71 & $1.06-13.03$ & $0.04 *$ \\
\hline Number of affected organs at diagnosis & 1.45 & $1.02-2.05$ & $0.04^{*}$ \\
\hline $\begin{array}{l}\text { Involvement of } \geq 4 \text { organs at diagnosis } \\
\text { (vs. } \leq 3 \text { organs) }\end{array}$ & 3.87 & $1.09-13.75$ & $0.04 *$ \\
\hline Serum creatinine level (mg/dL) & 1.82 & $1.06-3.12$ & $0.03^{*}$ \\
\hline $\begin{array}{l}\text { eGFR } \\
\left.\text { (per } 10 \mathrm{~mL} / \mathrm{min} / 1.73 \mathrm{~m}^{2}\right)\end{array}$ & 0.68 & $0.51-0.91$ & $0.01 *$ \\
\hline $\begin{array}{l}\text { eGFR }<45 \mathrm{~mL} / \mathrm{min} / 1.73 \mathrm{~m}^{2} \\
\text { (vs. } \geq 45 \mathrm{~mL} / \mathrm{min} / 1.73 \mathrm{~m}^{2} \text { ) }\end{array}$ & 8.48 & $2.42-29.79$ & $<0.01^{*}$ \\
\hline Serum CRP level (mg/dL) & 1.19 & $0.79-1.79$ & 0.41 \\
\hline $\begin{array}{l}\text { Serum lgG4 level } \\
\text { (per } 100 \mathrm{mg} / \mathrm{dL} \text { ) }\end{array}$ & 1.02 & $0.93-1.11$ & 0.70 \\
\hline Dyslipidemia & 1.16 & $0.33-4.12$ & 0.82 \\
\hline Hypertension & 1.68 & $0.47-5.96$ & 0.42 \\
\hline Diabetes Mellitus & 0.33 & $0.07-1.55$ & 0.16 \\
\hline Smoking History & 2.50 & $0.53-11.81$ & 0.25 \\
\hline CVD History & 2.08 & $0.54-8.06$ & 0.29 \\
\hline
\end{tabular}

Abbreviations: CRP: C-reactive protein; eGFR: estimated glomerular filtration rate; HR: hazard ratio; $95 \% \mathrm{Cl}$ : 95\% confidence interval.

\section{Figures}



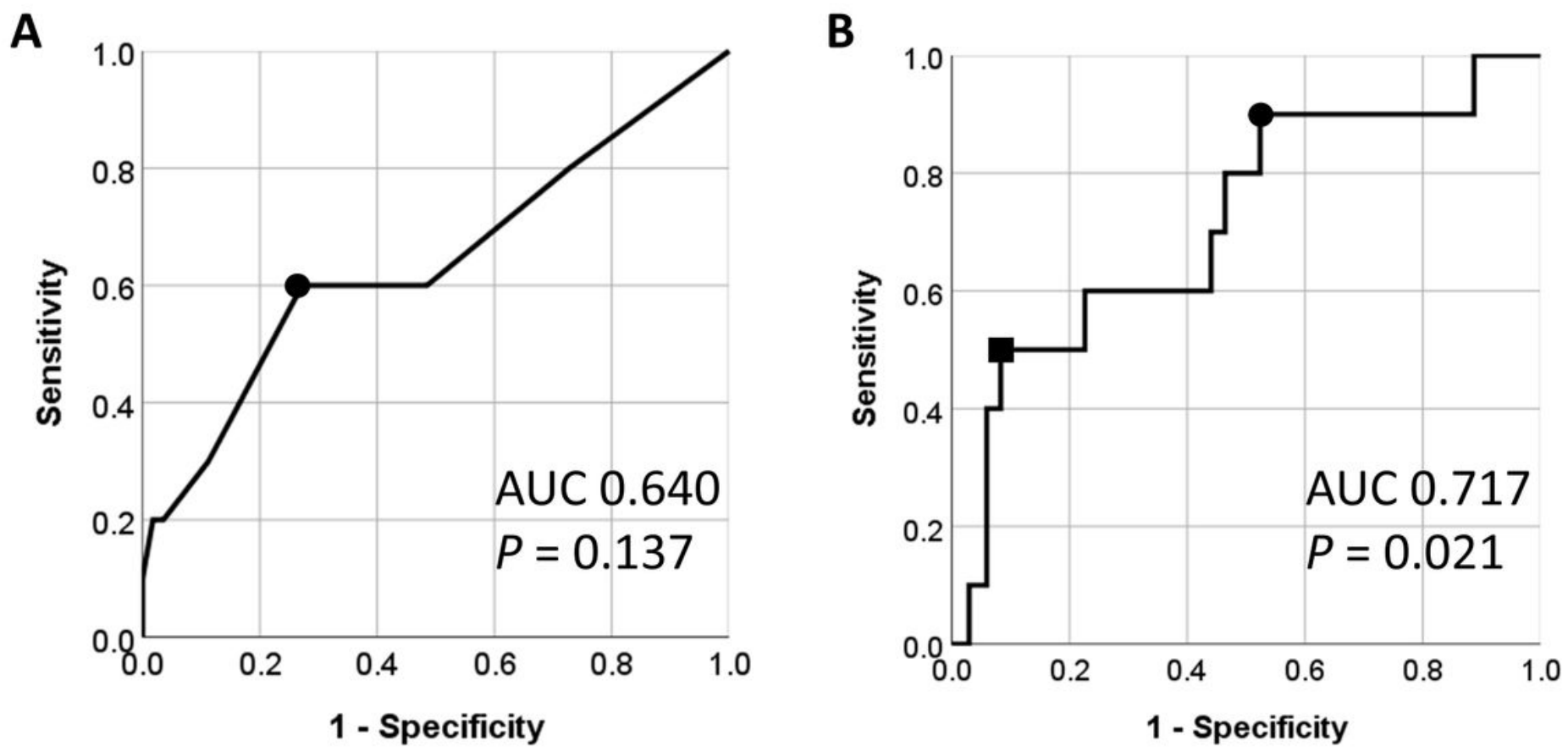

Figure 1

Receiver operating characteristic curve analysis. (A) Receiver operating characteristic (ROC) curves to identify the appropriate cut-offs of the number of involved organs for the prediction of mortality show that involvement of more than 3.5 organs yields a sensitivity of $60.0 \%$ and a specificity of $72.8 \%$ (circle). (B) ROC curves to identify the appropriate eGFR cut-offs for the prediction of mortality show that eGFR of less than $38.9 \mathrm{~mL} / \mathrm{min} / 1.73 \mathrm{~m} 2$ yields a sensitivity of $50.0 \%$ and a specificity of $91.7 \%$ (square) and eGFR of less than $73.6 \mathrm{~mL} / \mathrm{min} / 1.73 \mathrm{~m} 2$ yields a sensitivity of $90.0 \%$ and a specificity of $47.6 \%$ (circle). 

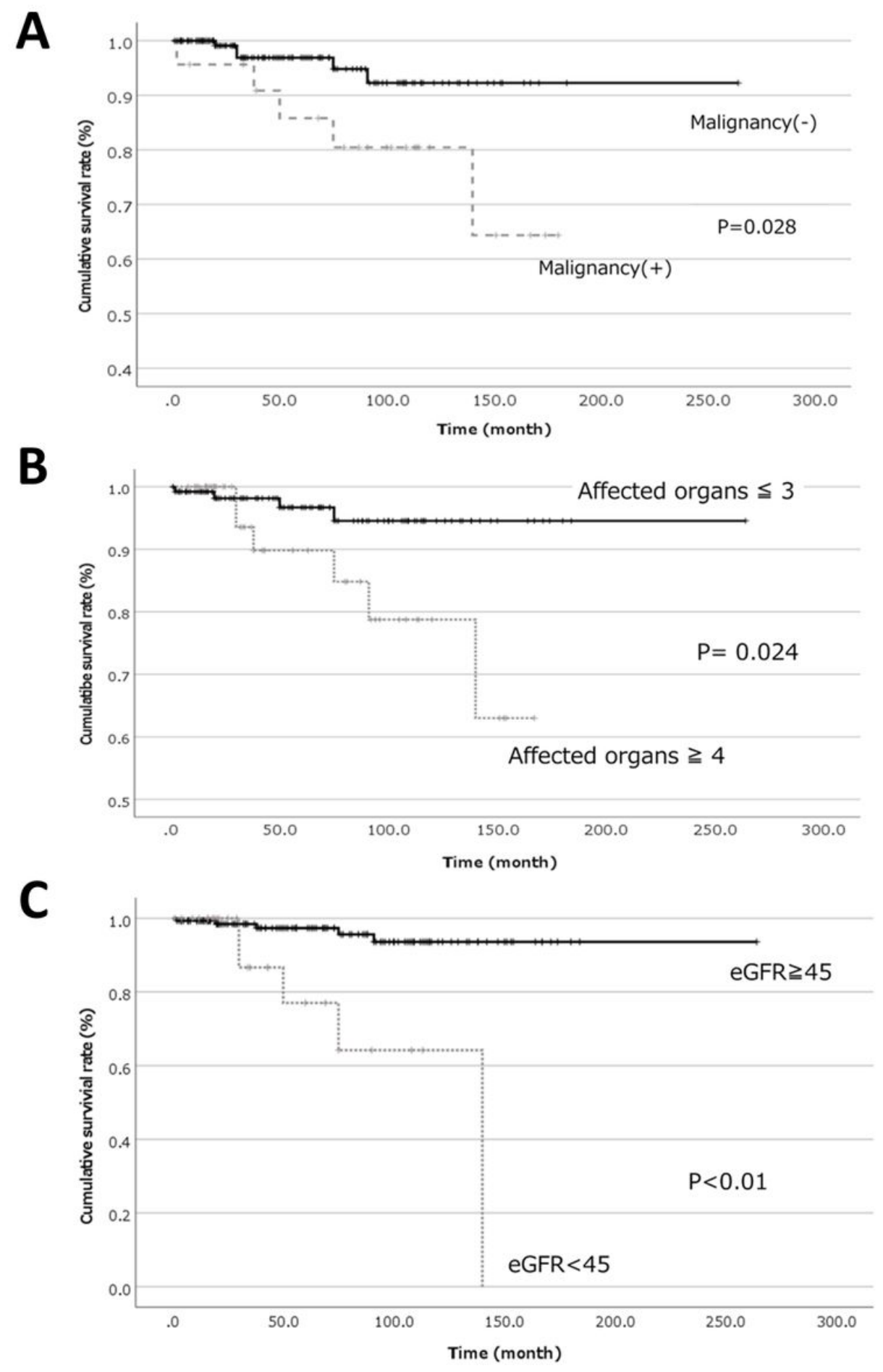

\section{Figure 2}

Kaplan-Meier event curves. Kaplan-Meier event curves demonstrated the mortalities in the groups with and without the risk factors. Malignancy $(A)$, multiple organ involvement in $\geq 4$ organs $(B)$, and renal dysfunction with eGFR $<45 \mathrm{~mL} / \mathrm{min} / 1.73 \mathrm{~m} 2$ (C) were significantly associated with lower survival rates. 